\title{
PEMASANGAN SMART SOLAR WATER PUMP SEBAGAI ALAT IRIGASI SAWAH DI DESA GAYAM KABUPATEN BOJONEGORO
}

\author{
Joke Pratilastiarso ${ }^{1}$, Lohdy Diana ${ }^{2}$, Erik Tridianto ${ }^{3}$, Arrad Ghani Safitra ${ }^{4}$ \\ Program Studi Sistem Pembangkit Energi, Departemen Teknik Mekanika dan Energi, Politeknik Elektronika Negeri \\ Surabaya, Surabaya, Indonesia \\ * Penulis Korespodensi : joke@ pens.ac.id
}

\begin{abstract}
Abstrak
Proses irigasi merupakan faktor penting untuk menghasilkan produk pertanian yang berkualitas. Namun, mitra yang merupakan petani mengalami permasalahan irigasi antara lain biaya operasional dan bahan bakar dimana mitra masih menggunakan pompa diesel, serta ketidakamanan peralatan terhadap pencurian. Oleh karena itu, tujuan dari kegiatan ini yaitu membantu mitra dalam hal irigasi lahan pertanian dengan membuat pompa air tenaga surya yang disebut dengan Smart Solar Water Pump yang dilengkapi dengan sistem kontrol ketinggian air dan sistem keamanan. Metode yang digunakan dalam kegiatan ini diawali dengan diskusi dan pancangan sistem Smart Solar Water Pump, perizinan dengan mitra, diskusi dan sosialisasi dengan mitra, pemasangan alat dan instalasi sistem keamanan dan kontrol ketinggian air, pengujian awal, pendampingan, evaluasi, dan monitoring. Hasil kegiatan ini antara lain penerapan energi terbarukan yaitu Smart Solar Water Pump telah dapat dilaksanakan sebagai alat irigasi pada lahan pertanian mitra, mitra telah mampu mengoperasikan Smart Solar Water Pump secara mandiri, setelah dilakukan monitoring diperoleh hasil sistem pada Smart Solar Water Pump masih beroperasi secara baik, sistem keamanan berupa Short Message Service (SMS) juga berjalan efektif.
\end{abstract}

Kata kunci: Irigasi, Pertanian, Smart Solar Water Pump, Sistem Kontro Ketinggian Air, Sistem Keamanan.

\begin{abstract}
The irrigation process is an important factor to produce quality agricultural products. However, partners who are farmers experience irrigation problems, including operational costs, and fuel cost where partners still used diesel pump, and also equipment was unsafety against theft. Therefore, this activity aims is to assist partners in the irrigation of agricultural land by making a solar water pump called the Smart Solar Water Pump which is equipped with a water level control system and a security system. The method used in this activity begins with discussions and views of the Smart Solar Water Pump system, licensing with partners, discussion and socialization with partners, installation of tools and installation of security and a water level control system, initial testing, mentoring, evaluation, and monitoring. The results of this activity include the application of renewable energy, namely the Smart Solar Water Pump which could be implemented as an irrigation tool on partner farms, partners were able to operate the Smart Solar Water Pump independently, after monitoring was carried out, the system on the Smart Solar Water Pump was still operating properly, the security system was Short Message Service (SMS). It was running effectively.
\end{abstract}

Keywords: Irrigation, Agricultural, Smart Solar Water Pump, Water Level Control System, Security System.

\section{PENDAhuluan}

Pertanian merupakan salah satu sektor yang sangat penting bagi Bangsa Indonesia. Pertanian merupakan penopang kehidupan bangsa yang berfungsi sebagai lumbung pangan. Namun, pada kenyataannya jumlah lahan pertanian di semakin berkurang tergantikan dengan pembangunan industri maupun perumahan. Hal tersebut terjadi karena para petani tidak mampu bertahan mengatasi mahalnya biaya untuk mengolah lahan pertanian. Permasalahan biaya salah satunya adalah pengairan untuk lahan pertanian. Pengairan atau dikenal dengan istilah irigasi yang rutin merupakan hal yang wajib bagi dan tidak dapat dipungkiri untuk keberlangsungan hidup tanaman pertanian. Musim 
kemarau dan mahalnya biaya operasional merupakan permasalahan yang harus dihadapi oleh para petani. Oleh karena itu diperlukan sebuah solusi untuk membantu para petani memecahkan masalah irigasi agar produksi pertanian dapat terus berjalan bahkan mengalami peningkatan.

Dwi (2020) menyatakan lahan pertanian di Indonesia akan semakin berkurang dipengaruhi oleh pendapatan petani. Oleh karena itu pengelolaan pertanian untuk meningkatkan pendapatan petani harus dilakukan. Eko (2020) menyatakan pembangunan dan perencanaan sistem irigasi diperlukan khususnya di daerah-daerah mengingat dengan lancarnya proses irigasi maka dapat memperkuat pertanian sebagai wujud ketahanan pangan.

Menurut kamus besar Bahasa Indonesia (2020) menyatakan irigasi adalah pengaturan pembagian atau pengaliran air menurut sistem tertentu untuk sawah dan sebagainya.

M.Dzulkifli (2016) menyatakan pertumbuhan dan perkembangan tanaman bisa terhambat atau terganggu karena kebutuhan air pada tanaman tidak tercukupi. Sehigga diperlukan pengaturan ketinggian air merupakan faktor penting salah satunya dengan cara menggunakan sistem kontrol otomatis berbasis wireless sensor network.

Sistem kontrol saat ini sedang banyak diterapkan dan mulai masuk kedalam bidang pertanian seperti penerapan buka tutup pintu irigasi lahan pertanian menggunakan Arduino seperti yang telah dilakukan oleh Chomy (2020).

Pengabdian masyarakat kali ini dilakukan di Jawa Timur tepatnya di Kabupaten Bojonegoro yang merupakan salah satu daerah yang masih memiliki lahan pertanian yang sangat luas. Salah satunya lahan pertanian yang dimiliki oleh Mitra pengabdian masyarakat ini yaitu Ibu Kasinem dengan alamat lahan pertanian berada di Dusun Sumur Pandan RT.00, RW.00, Desa Gayam Kecamatan Gayam, Kabupaten Bojonegoro Jawa Timur dengan luas lahan sawah sebesar $5963 \mathrm{~m}^{2}$. Apabila dilihat dari tampilan satelit melalui Google Map, lahan pertanian yang dimiliki mitra ditunjukkan seperti pada Gambar 1.

Kondisi mitra sebelum pengabdian masyarakat ini dilakukan yaitu mengalami permasalahan mengenai sistem irigasi. Sistem irigasi yang digunakan mitra masih menggunakan pompa diesel. Penggunaan pompa diesel memerlukan biaya operisonal bahan bakar dan biaya trasportasi untuk membawa pompa dari rumah petani ke lahan pertanian setiap kali ingin menyalakan pompa. Permasalahan lain yaitu apabila pompa diesel tidak diawasi secara langsung dan terus menerus maka pompa dapat hilang dicuri karena area pertanian yang sangat luas dan sepi seperti beberapa kejadian pencurian yang pernah terjadi di daerah tersebut.

Berdasarkan permasalahan yang dihadapi oleh mitra dan perbaikan sistem berdasarkan kajian literatur yang telah dilakukan maka pada pengabdian masyarakat ini memberikan beberapa solusi untuk menyelesaikan permasalahan tersebut yaitu dengan memasang Smart Solar Water Pump. Smart Solar Water Pump merupakan pompa air bertenaga surya yang telah dilengkapi dengan sistem kontrol ketinggian air, sistem kontrol daya pompa, sistem kontrol debit air, sistem keamanan dari pencuri berbasis Short Message Service (SMS), serta sistem keamanan dari pengaruh cuaca dan lingkungan.

Tujuan dari kegiatan ini adalah membantu permasalahan mitra yaitu petani mengenai sistem irigasi lahan pertanian khususnya ketika memasuki musim kemarau. Setelah pemasangan Smart Solar Water Pump ini mitra dapat meningkatkan hasil panen dan meringankan kerja mitra sekaligus mengurangi rasa kewaspadaan mitra terhadap pencurian alat irigasi.

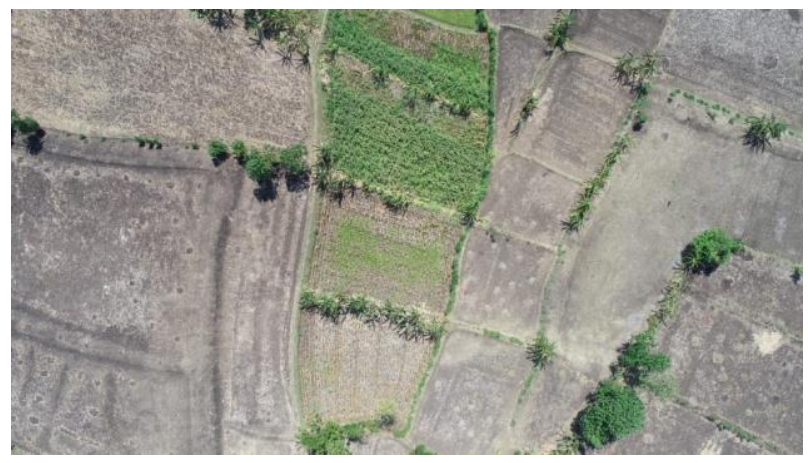

Gambar 1. Lahan pertanian mitra

\section{BAHAN DAN METODE}

Metode yang digunakan pada kegiatan pengabdian ini antara lain:

1. Diskusi dan pancangan sistem Smart Solar Water Pump.

Kegiatan diskusi dilakukan di Politeknik Elektronika Negeri Surabaya dengan membentuk tim yang terdiri dari beberapa dosen dengan keahlian masing-masing.

2. Perizinan dengan mitra.

Kegiatan perijinan yang bertujuan untuk mencapai kesepakatan untuk dilakasanakannya kegiatan pengabdian masyarakat di lahan pertanian mitra.

3. Diskusi dan sosialisasi dengan mitra.

Kegiatan diskusi dengan mitra dilakukan untuk mengetahui permasalahan apa saja yang sedang dihadapi oleh mitra mengenai irigasi sehingga dapat diberika solusi untuk menyelesaikan permasalahan tersebut dengan melakukan sosialisasi maanfaat dari kegiatan pengabdian masyarakat ini.

4. Pemasangan alat dan instalasi sistem keamanan dan sistem kontrol.

Kegiatan ini merupakan realisasi terhadap pemecahan masalah pengairan yang sedang dihadapi oleh mitra yang merupakan kerjasama semua tim dari program studi Sistem Pembangkit Energi, Politeknik Elektronika Negeri Surabaya. 
5. Pengujian awal.

Kegiatan ini diperlukan untuk mengetahui kinerja dari Smart Solar Water Pump sehingga apabila terjadi permasalahan secara teknis dapat segera dilakukan perbaikan.

6. Pendampingan.

Kegiatan ini bertujuan untuk memberikan arahan dan pengetahuan kepada mitra agar mitra dapat mengoperasikan Smart Solar Water Pump secara mandiri dan benar.

7. Evaluasi dan monitoring.

Kegiatan ini dilakukan selang tiga minggu setelah kegiatan satu sampai kegiatan enam dilakukan. Kegiatan evaluasi dan monitoring bertujuan untuk memastikan bahwa Smart Solar Water Pump masih bekerja dengan baik. Kegiatan ini sekaligus merupakan perbaikan terhadap sistem Smart Solar Water Pump dengan menampung masukkan maupun keluhan dari mitra setelah menggunakan Smart Solar Water Pump secara mandiri.

\section{HASIL DAN PEMBAHASAN}

Hasil yang diperoleh pada kegiatan pengabdian ini antara lain:

A. Diskusi dan peracangan bersama tim.

Kegiatan diskusi ditunjukkan seperti pada Gambar 2, kegiatan tersebut dilaksanakan pada tanggal 30 Agustus 2020 menghasilkan beberapa keputusan antara lain: topik pengabdian masyarakat, mitra yang akan bekerjasama, rancangan sistem alat irigasi, dan jadwal kegiatan. Topik yang dipilih adalah mengenai irigasi lahan pertanian menggunakan energi terbarukan yaitu pompa air bertenaga surya yang dilengkapi dengan sistem kontrol ketinggian air, sistem kontrol daya pompa, sistem control debit air, dan sistem keamanan.

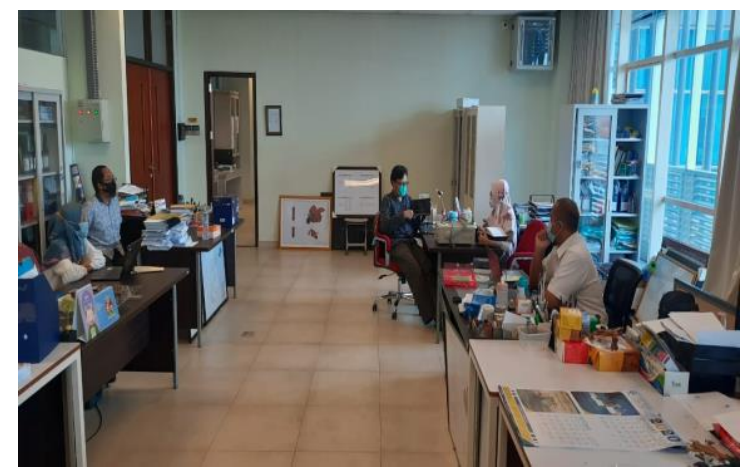

Gambar 2. Kegiatan diskusi membahas rancangan sistem Smart Solar Water Pump.

Tim terdiri dari dosen dan teknisi program studi Sistem Pembangkit Energi, Politeknik Elektronika Negeri Surabaya. Penetapan pembagian tim dalam membuat sistem Smart Solar Water Pump, tim tersebut terdiri dari:

a. Tim kontrol yaitu tim yang merancang sistem kontrol daya pompa, kontrol debit air, dan sistem keamanan berbasis Short Message Service (SMS).

b. Tim mekanik yaitu tim yang menetukan posisi pompa berdasarkan perhitungan mekanika fluida dan merancang keamanan terhadap pengaruh cuaca dan pengaruh lingkungan.

c. Tim penunjang yaitu tim yang bertugas mengurus perijinan dengan mitra, membuat jadwal kegiatan, dan membantu tim kontrol dan tim mekanik dalam menjalankan tugasnya.

Pada saat diskusi tim telah memiliki gambar lahan pertanian yang dimiliki oleh calon mitra. Hal tersebut bertujuan untuk melakukan pemetaan rancangan awal untuk selanjutnya akan disampaikan kepada mitra melalui perizinan secara resmi atau pada kegiatan dua. Rancangan sistem ditunjukkan pada Gambar 3. Sistem menggunakan remote sensing berbasis wireless mini scada, dimana di dalamnya menggunakan pompa air yang memanfaatkan tenaga surya (melalui solar panel) yang aktif dan tidaknya mendapat informasi dari wireless sensor menggunakan tenaga matahari juga yang terpasang di ujung ujung sawah, sehingga ketika sawah sudah mencukupi pengairannya pompa akan mati secara otomatis. Sistem Smart Solar Water Pump dipasang permanen sehingga tidak perlu dipindahkan dengan demikian mitra tidak perlu mengeluarkan biaya transportasi untuk memindahkan alat tersebut dari rumah menuju lahan pertanian. Untuk pengamanannya akan diberikan pagar pengaman serta gembok dan dilengkapi alarm serta notifikasi SMS yang akan dikirim ke mitra seandainya pompa atau salah satu komponen Smart Solar Water Pump dicuri.

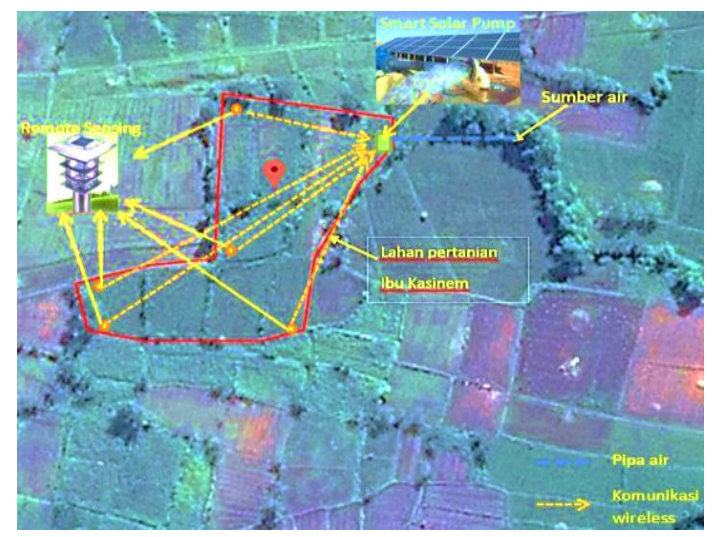

Gambar 3. Rancangan sistem pada lahan pertanian mitra. 
B. Perizinan dengan mitra.

Perizinan diperoleh melalui media komunikasi seluler dan diperoleh hasil mitra menyetujui yaitu pengabdian masyarakat akan dilaksanakan di lahan pertanian yang berada di Dusun Sumur Pandan RT.00, RW.00, Desa Gayam Kecamatan Gayam, Kabupaten Bojonegoro Jawa Timur dengan luas lahan sawah sebesar $5963 \mathrm{~m}^{2}$.

C. Diskusi dan sosialisasi dengan mitra.

Sosialisasi dilakukan secara langsung di rumah mitra pada tanggal 12 Agustus 2020 seperti ditunjukkan pada Gambar 4. Pada kegiatan tersebut mitra menyampaikan beberapa kendala antara lain: sumber air yang jaraknya cukup jauh dari lahan pertanian mitra, jumlah debit air yang tidak terlalu besar, ketinggian air yang tidak dapat diatur sehingga kadang air terlalu banyak mengairi lahan pertanian.

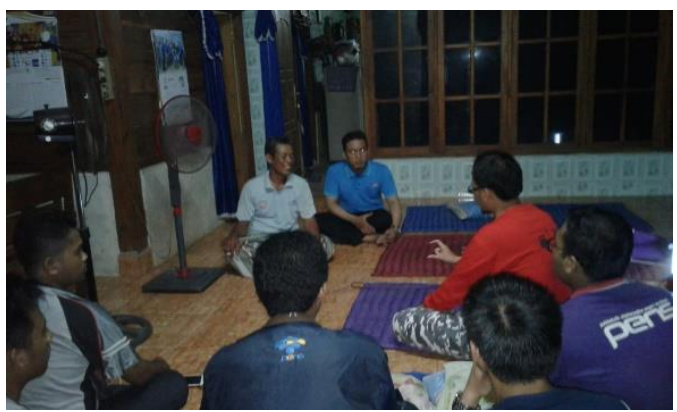

Gambar 4. Kegiatan sosialisasi dengan mitra.

D. Pemasangan alat dan instalasi sistem keamanan, sistem kontrol ketinggian air, dan sistem kontrol daya pompa.

Kegiatan pemasangan Smart Solar Water Pump dilaksanakan pada tanggal 13 Agustus 2020. Sebelum memasang pipa pada lahan pertanian, kegiatan awal yang dilakukan adalah memastikan semua komponen dapat beroperasi dengan baik. Hal tersebut bertujuan agar pekerjaan saat di lahan pertanian berjalan efektif. Gambar 5 menunjukkan pemeriksaan daya pada baterai Smart Solar Water Pump yang dilakukan di rumah mitra sebelum keesokkan harinya berangkat ke lahan pertanian. Kegiatan ini menghasilkan instalasi pipa air yang terpasang di lahan pertanian. Pipa tersebut terpasang dari sumber air hingga lahan pertanian mitra. Proses pemasangan pipa ditunjukkan seperti pada Gambar 6.

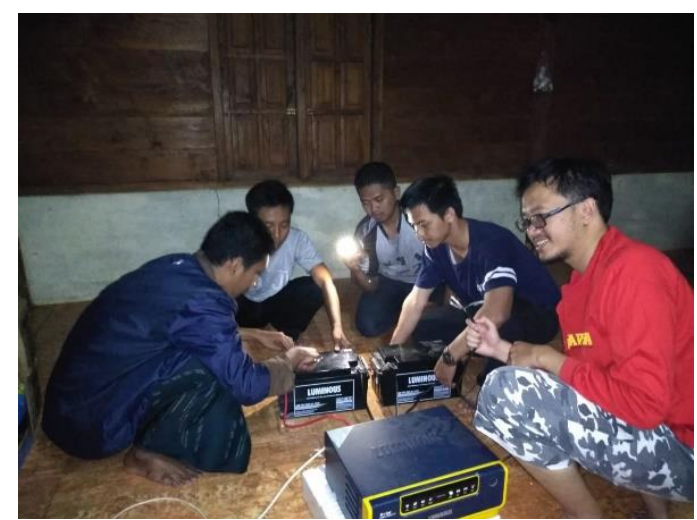

Gambar 5. Pemeriksaan komponen alat Smart Solar Water Pump.

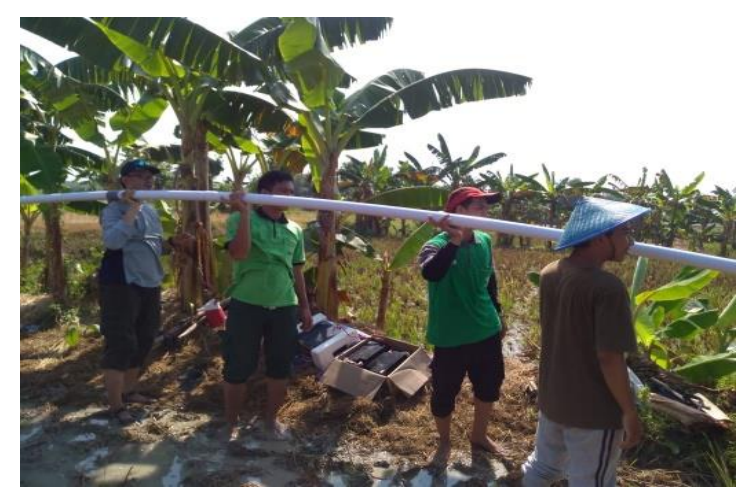

Gambar 6. Pemasangan instalasi Smart Solar Water Pump pada lahan pertanian.

E. Pengujian awal

Pengujian awal dilakukan pada sore hari setelah baterai menyimpan cukup energi untuk menjalankan pompa. Pada kegiatan ini pompa telah terpasang pada posisi yang telah diperhitungkan sebelumnya. Proses pemasangan pompa ditunjukkan seperti pada Gambar 7. Setelah semua instalasi terpasang, tahap selanjutnya adalah uji coba alat. Pada kegiatan ini pompa dapat berfungsi dengan baik ditunjukkan seperti pada Gambar 8 .

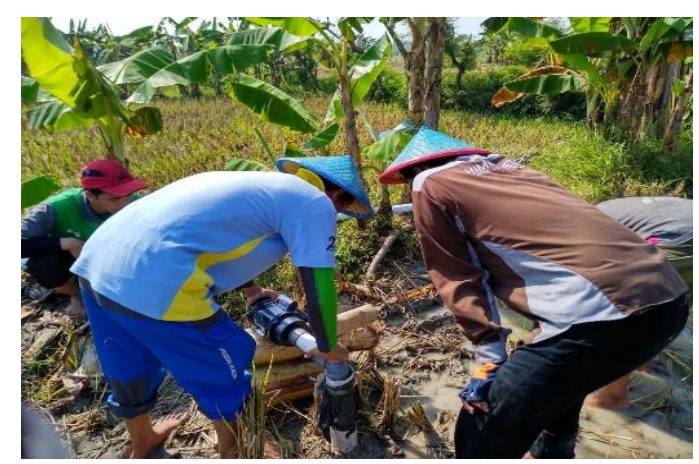

Gambar 7. Pemasangan pompa. 


\section{$\sqrt{000}$}

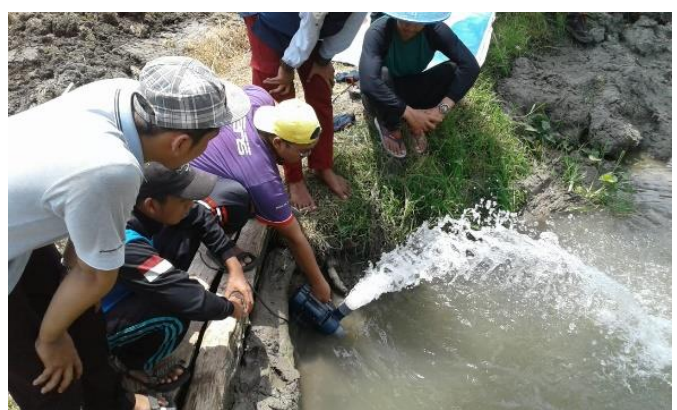

Gambar 8. Kegiatan uji coba pompa air.

F. Pendampingan

Kegiatan pendampingan dilakukan dengan memberikan arahan kepada mitra, arahan tersebut antara lain: cara mengoperasikan Smart Solar Water Pump, cara perawatan pompa agar tidak cepat mengalami kerusakan, hingga mempraktekkan cara mengatasi apabila ketinggian di sumber air sangat rendah dimana hal tersebut akan terjadi saat musim kemarau. Kegiatan pendampingan bersama mitra ditunjukkan seperti pada Gambar 9. Pada kegiatan tersebut juga mensimulasikan seandainya pompa dicuri. Apabila pada kondisi stabil maka sensor tegangan akan menunjukkan angka 12 Volt. Namun, apabila pompa tersebut mengalami gangguan maka tegangan sensor yang awalnya 12 Volt akan mengalami penurunan. Ketika penurunan tegangan sensor terjadi maka sistem kontrol keamanan akan secara otomatis mengirimkan Short Message Service (SMS) kepada mitra sehingga mitra dapat melakukan pengecekan langsung untuk memastikan kondisi pompa. Short Message Service yang diterima ke handphone mitra ditunjukkan seperti pada Gambar 9. Pada Gambar tersebut menunjukkan sensor tegangan menurun sebesar 5.87 Volt.

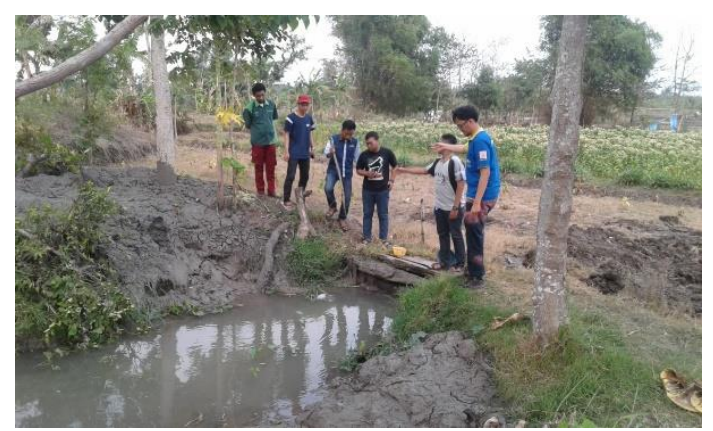

Gambar 9. Kegiatan pendampingan bersama mitra.

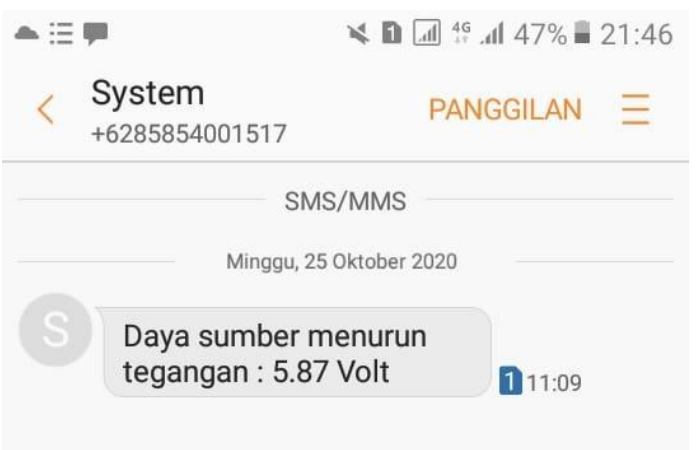

Gambar 10. Sistem keamanan berupa Short Message Service (SMS).

G. Evaluasi dan monitoring

Kegiatan evaluasi dilakukan pada tanggal 27 September 2020 dimana tim melakukan pengecekan langsung terhadap sistem Smart Solar Water Pump. Pada kegiatan tersebut diperoleh hasil di antaranya adalah data sensor tengangan yang dihasilkan seperti ditunjukkan pada Tabel 1. Data tegangan sensor ini merupakan penurunan setelah dilakukan pemasangan secara paralel dengan daya yang diperlukan untuk menyalakan pompa yaitu sebesar 220 Volt. Tabel 1 menunjukkan data hasil pengukuran sensor tegangan sebanyak sepuluh kali dan diperoleh hasil bahwa hanya sebanyak dua kali data menunjukkan angka di bawah 12 Volt. Kemudian dilakukan pengecekkan untuk mengetahui kondisi sensor ketinggian air. Setelah dilakukan pengambilan data sebanyak sepuluh kali diperoleh hasil bahwa semua data menunjukkan keakuratan antara data seharusnya dengan data yang terbaca dengan waktu respon terlama yaitu lima detik. Berdasarkan hal tersebut menujukkan sensor ketinggian masih berjalan dengan baik. Sedangkan sistem kontrol pada kotak panel yang diamati ditunjukkan pada Gambar 11. Kegiatan monitoring selanjutnya adalah melakukan pengecekkan terhadap sensor keamanan dan diperoleh hasil seperti ditunjukkan pada Tabel 3 yang merupakan waktu respon modul komunikasi. Sama seperti sistem kontrol lainnya pengambilan data dilakukan sebanyak sepuluh kali dan diperoleh hasil berdasarkan Tabel 3 waktu respon tercepat adalah 30 detik untuk jarak satu meter dan respon terlama adalah 6 menit untuk jarak terjauh yaiu 4 meter. 
Tabel 1. Data sensor tegangan $=12 \mathrm{~V} \mathrm{Dc}$.

\begin{tabular}{ccc}
\hline No & $\begin{array}{c}\text { Data } \\
\text { seharusnya }\end{array}$ & $\begin{array}{c}\text { Data } \\
\text { Pengukuran }\end{array}$ \\
\hline 1 & $12 \mathrm{~V}$ & $11,8 \mathrm{~V}$ \\
2 & $12 \mathrm{~V}$ & $12.1 \mathrm{~V}$ \\
3 & $12 \mathrm{~V}$ & $12 \mathrm{~V}$ \\
4 & $12 \mathrm{~V}$ & $12 \mathrm{~V}$ \\
5 & $12 \mathrm{~V}$ & $12 \mathrm{~V}$ \\
6 & $12 \mathrm{~V}$ & $11.9 \mathrm{~V}$ \\
7 & $12 \mathrm{~V}$ & $12.1 \mathrm{~V}$ \\
8 & $12 \mathrm{~V}$ & $12 \mathrm{~V}$ \\
9 & $12 \mathrm{~V}$ & $12 \mathrm{~V}$ \\
10 & $12 \mathrm{~V}$ & $12 \mathrm{~V}$ \\
\hline
\end{tabular}

Tabel 2. Data sensor ketinggian air (LIMIT SWITCH).

\begin{tabular}{cccc}
\hline No & $\begin{array}{c}\text { Data } \\
\text { Seharusnya }\end{array}$ & $\begin{array}{c}\text { Data yang } \\
\text { terbaca }\end{array}$ & $\begin{array}{c}\text { Waktu } \\
\text { (detik) }\end{array}$ \\
\hline 1 & HIGH & HIGH & 5 \\
2 & HIGH & HIGH & 3 \\
3 & LOW & LOW & 4 \\
4 & LOW & LOW & 3 \\
5 & LOW & LOW & 2 \\
6 & HIGH & HIGH & 4 \\
7 & LOW & LOW & 4 \\
8 & HIGH & HIGH & 5 \\
9 & HIGH & HIGH & 5 \\
10 & LOW & LOW & 3 \\
\hline
\end{tabular}

Tabel 3. Modul komunikasi.

\begin{tabular}{ccc}
\hline No & Jarak (meter) & Waktu(menit) \\
\hline 1 & 1 & 30 detik \\
2 & 1 & 45 detik \\
3 & 1 & 30 detik \\
4 & 2 & 1 menit \\
5 & 2 & 1 menit 30 detik \\
6 & 2 & 1 menit \\
7 & 3 & 4 menit \\
8 & 3 & 4 menit 20 detik \\
9 & 3 & 6 menit \\
10 & 4 &
\end{tabular}

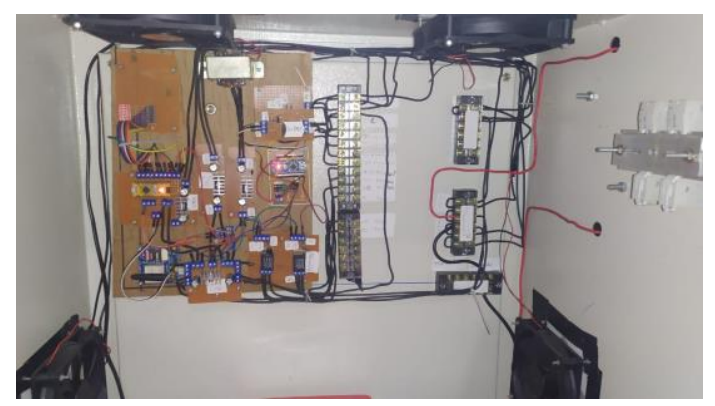

Gambar 11. Sistem control pada kotak panel.

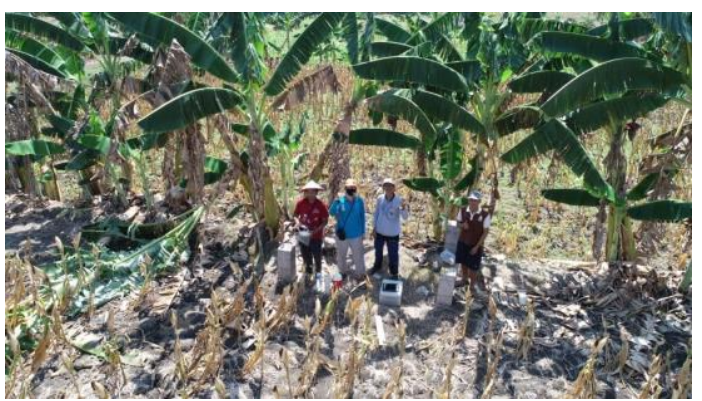

Gambar 12. Kegiatan pengamatan lahan pertanian menggunakan drone.

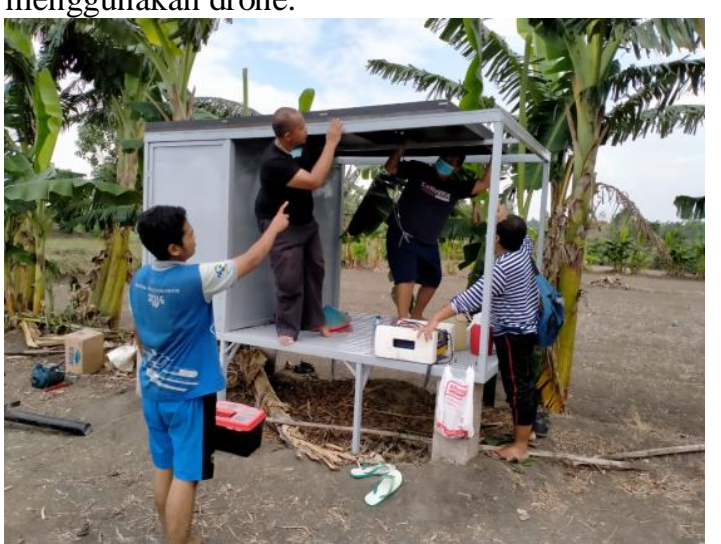

Gambar 13. Kegiatan pemasangan rumah pompa tenaga surya di tengah lahan pertanian mitra.

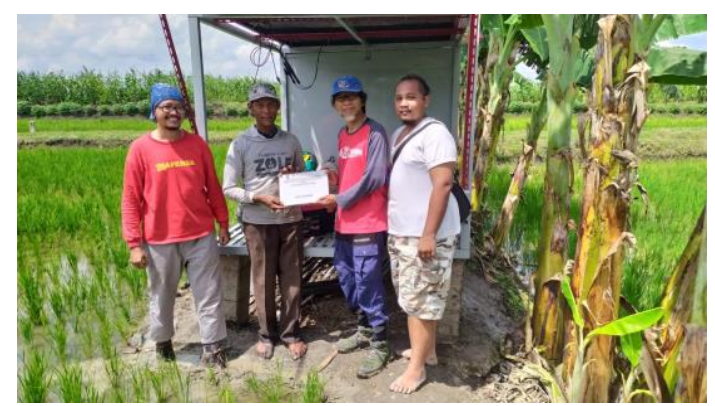

Gambar 14. Serah terima rumah pompa tenaga surya oleh tim kepada Mitra.

Kegiatan evaluasi dan monitoring diakhiri dengan meminta pendapat mitra kemudian mitra menyampaikan beberapa hasil evaluasi dari pemakaian Smart Solar Water Pump yang telah dijalankan selama beberapa pekan. Mitra menyampaikan bahwa masih diperlukan sebuah tempat yang teduh di area Smart Solar Water Pump. Hal tersebut bertujuan agar mitra dapat berteduh sekaligus mengamati proses irigasi pada lahan pertanian. Berdasarkan permintaan mitra tim akan berusaha menindaklanjuti untuk membuat tempat yang teduh disekitar area Smart Solar Water Pump diawali dengan melakukan pemetaan menggunakan 
drone seperti ditunjukkan pada Gambar 12 yang dilakukan bersama mitra.

Kegiatan selanjutnya adalah membangun rumah Smart Solar Water Pump. Seperti ditunjukkan paga Gambar 13, pemasangan dilakukan oleh tim pada lahan pertanian mitra. Kegiatan tersebut dilakukan selama lima hari. Kegiatan diakhiri dengan melakukan serah terima rumah Smart Solar Water Pump dari tim pengabdian masyarakat program studi Sistem Pembangkit Energi, Politeknik Elektronika Negeri Surabaya kepada mitra seperti ditunjukkan pada Gambar 14.

\section{KESIMPULAN}

1. Penerapan energi terbarukan yaitu Smart Solar Water Pump telah dapat dilaksanakan sebagai alat irigasi pada lahan pertanian mitra.

2. Mitra telah mampu mengoperasikan Smart Solar Water Pump secara mandiri.

3. Setelah dilakukan kegiatan monitoring, sistem kontrol ketinggian air, sistem kontrol daya pompa pada Smart Solar Water Pump masih beroperasi secara baik.

4. Sistem keamanan berupa Short Message Service (SMS) berjalan efektif.

\section{UCAPAN TERIMA KASIH}

Puji syukur Alhamdulillah dipanjatkan kepada ALLAH SWT karena kegiatan ini dapat dilaksanakan serta kepada Politeknik Elektronika Negeri Surabaya yang telah memberikan dukungan berupa dana pengabdian masyarakat, ucapan terima kasih juga diberikan kepada mitra yang telah bekerjasama untuk menerapkan energi terbarukan, dan kepada segenap keluarga tim dosen dari program studi Sistem Pembangkit Energi.

\section{DAFTAR PUSTAKA}

Suprastyo, D., Siregar, H., \& Mulatsih, S. (2020). Analisis Distribusi Pemilikan Lahan Pertanian dan Pendapatan Usahatani di Kabupaten Karawang. TATA LOKA BIRO PENERBIT PLANOLOGI UNDIP, Vol. 22 No. 1.

Aristanto, E., Hidayatullah, S., Dinata, C., \& Prabowo, K. A. (2020). PERANCANGAN DASHBOARD PERENCANAAN PEMBANGUNAN IRIGASI DAERAH MENDUKUNG KETAHANAN PANGAN. Jurnal Pengabidan Kepada Masyarakat Membangun Negeri, Vol. 4 No. 1.

Kamus Besar Bahasa Indonesia. 2020. Jakarta: Balai Pustaka.

Alel, Dwi Chomy, \& Aswardi (2020). Rancang Bangun Buka Tutup Pintu Air Otomatis Pada Irigasi Sawah Berbasis Arduino dan Monitoring Menggunakan Android. JTEV, Vol. 6 No. 1.

S., M. Dzulkifli, Rivai, M., \& Suwito (2016). Rancang Bangun Sistem Irigasi Tanaman Otomatis Menggunakan Wireless Sensor Network. JURNAL TEKNIK ITS, Vol. 5 No. 2. 